\title{
Experiencias didácticas para promover el aprendizaje de la ecología a través del trabajo de campo
}

Didactic experiences to promote the learning of ecology through field work

\section{Antonio Vera}

ajvera68@gmail.com

Código ORCID: 0000-0002-8298-9750

\section{Universidad del Zulia}

Maracaibo - Venezuela
4 Articulo aceptado en septiembre 2020

- Arbitrado en octubre 2020

< Publicado en enero 2021

Se describieron experiencias didácticas para promover el aprendizaje de la Ecología a través del trabajo de campo. La metodología fue descriptiva, de campo, no experimental y documental. Los trabajos de campo permitieron mantener a los estudiantes en contacto directo con la naturaleza, realizar actividades exploratorias, descubrir y seleccionar situaciones de aprendizaje. Se promovió la discusión entre los participantes para el enriquecimiento del conocimiento individual y grupal. También se emplearon las estrategias explicitación de objetivos, cuadro C-Q-A, focal introductoria, señalizaciones y discusiones guiadas para adquirir nuevos conocimientos en comparación a las ideas previas, el reconocimiento de características anatómicas modificadas, la identificación de niveles ecológicos, la aclaratoria de incógnitas difíciles de descifrar y la exposición de propuestas hasta obtener la explicación concluyente del tema. La observación directa y vivencial resultó la herramienta principal para que los estudiantes obtuvieran deslumbrantes aportes didácticos del campo. Las estrategias empleadas promovieron la consolidación de aprendizajes ecológicos.

Palabras clave: Aprendizaje; bosque xerófilo; ideas previas; manglar; trabajo de campo

Abstract

Didactic experiences to promote the learning of Ecology through field work were described. The methodology was descriptive, field, nonexperimental and documentary. The field work allowed students to keep in direct contact with nature, perform exploratory activities, discover and select learning situations. Discussion was promoted among the participants for the enrichment of individual and group knowledge. Strategies were also used to explain objectives, CQA chart, introductory focus, signage and guided discussions to acquire new knowledge compared to previous ideas, recognition of modified anatomical features, identification of ecological levels, clarification of unknowns difficult to decipher and the presentation of proposals until obtaining the conclusive explanation of the subject. Direct and experiential observation was the main tool for students to obtain dazzling contributions from the field. The strategies employed promoted the consolidation of ecological learning.

Keywords: Learning; xerophytic forest; previous ideas; mangrove; field work 
INTRODUCCIÓN

La importancia de la enseñanza y el aprendizaje de las ciencias naturales se fundamenta en que éstas constituyen un conjunto de áreas del conocimiento que permiten y ayudan al hombre a establecer contacto, indagar e interpretar el grandioso ambiente que le circunda denominado entorno fisicoquímico-biótico natural (Vera, 2007).

En este mismo sentido, la ecología orienta su estudio en las relaciones entre los seres vivos y su entorno, es decir, establece una conjugación de lo biótico, lo abiótico y el hábitat o ambiente geográfico de manera interdependiente. Por lo tanto, esta disciplina se convierte en la ciencia de las interacciones organizadoras entre el biotopo y la biocenosis (Di Salvo et al., 2009).

Esto último se centra en destacar el reconocimiento de los ecosistemas, unidad básica de estudio de la ecología, como sistemas complejos que revelan y explican que manera funciona la naturaleza, y por ello no pueden ser abordados de forma reduccionista (partes desarticuladas); ya que las relaciones establecidas, determinan finalmente la esencia del sistema (visión holística de la ecología) (Di Salvo et al., 2009).

Esto justifica, de forma considerable, la selección y el uso del campo (el ambiente, el entorno $o$ el espacio geográfico), por parte el docente, como el escenario didáctico por excelencia para aplicar su intencionalidad didáctica y así promover el aprendizaje de la ecología a través de la estrategia trabajo de campo.

El éxito del uso del trabajo de campo depende en gran parte de la experiencia didáctica del docente en cuanto al manejo del contenido disciplinar, el conocimiento fisiográfico del área de estudio a abordar, la aplicación de otras estrategias didácticas en el campo, la organización de dicha actividad práctica-vivencial, la evidencia de un claro enfoque epistemológico que viabilice todo el accionar del docente, entre otros aspectos. De tal manera, que la praxis docente concentra una experiencia que conlleva a la reflexión dinámica del proceso de enseñanza para responder a las limitaciones o debilidades de los aprendizajes (Acosta Faneite y Boscán Andrade, 2014).

Por su parte, el propio trabajo de campo muestra atributos poderosos que lo promocionan como una estrategia didáctica valiosa de vanguardia, digna de ponerse en práctica en la educación formal para la enseñanza y el aprendizaje de las ciencias naturales en general y de la ecología de forma particular. Estas afirmaciones cobran su esencia propia en las ideas de Sauwéns (1988), quien sostiene que la aplicación del trabajo de campo promueve el aprendizaje de la dinámica espacial de la realidad del educando, las interrelaciones existentes entre los elementos que componen el ambiente y su problemática, la asociación del 
estudiante con su realidad entre a otros aspectos.

En este orden de ideas, Fernández Manzanal y Casal Jiménez (1995) también hacen énfasis en los atributos que sustentan la importancia del trabajo de campo, al sostener que la adquisición de los conocimientos de ecología no serían garantía suficiente para un cambio duradero de actitudes y conducta ambientalista si los mismos no fueran acompañados de experiencias que involucren, además de la inteligencia, otros aspectos de los educandos como sus emociones, vivencias sobre el campo en un ambiente de aprendizaje, entre otros elementos.

El objetivo de este trabajo es describir experiencias didácticas para promover el aprendizaje de la ecología a través del trabajo de campo.

\section{MATERIALES Y MÉTODOS}

La investigación se desarrolló atendiendo a una metodología descriptiva, de campo, no experimental y documental.

La fase práctica-vivencial de la investigación consistió en la realización de cuatro trabajos de campo, dos al bosque xerófilo y dos al bosque de manglar de la Reserva de Fauna Silvestre Ciénaga de La Palmita e Isla de Pájaros, localizada en el Municipio Santa Rita del Estado Zulia, Venezuela en junio de 2018 (I periodo académico) y octubre de 2018 (II periodo académico).

Los participantes de los trabajos de campo fueron estudiantes de la cátedra Ecología de la Mención Biología de la Escuela de Educación de la Facultad de Humanidades y Educación de la Universidad del Zulia, y los autores de esta investigación fungieron como profesores (mediadores de dichas actividades didácticas), y los mismos se desempeñan como docentes en ejercicio de la mencionada cátedra.

Las áreas de estudio (entornos fisicoquímico-bióticos naturales) empleadas para los trabajos de campo se seleccionaron y exploraron previamente a objeto de conocer las características y atributos de los ecosistemas. En virtud de ello, se estableció un sendero (ruta o recorrido) a transitar durante la actividad de 1,3 a 1,5 km aproximadamente de longitud y se delimitaron estaciones (precisión y fijación de espacios geográficos para la realización de las actividades prácticas).

$\mathrm{Se}$ emplearon dos grupos de estudiantes, correspondiendo uno para cada periodo académico de 2018. Cada grupo estuvo integrado por 24 estudiantes, organizados en equipos de tres (3) integrantes para la realización de las actividades.

Los trabajos de campo se llevaron a cabo a través del desplazamiento e 
indagación in situ, por parte de los equipos de estudiantes, para hacer reconocimientos, descripciones, planteamientos de preguntas, formulación de hipótesis, búsqueda de explicaciones a las situaciones problema, ejemplificaciones, recolectas de muestras bióticas, medición de parámetros fisicoquímicos y análisis de los aspectos y contenidos ecológicos vistos (tratados y manejados) previamente en clase y presentes de manera ejemplificada en el ambiente circundante.

La información obtenida por cada equipo fue procesada y discutida por sus miembros y expuestas en mini sesiones plenarias ante el resto de los participantes. También se aplicaron las estrategias didácticas explicitación de objetivos, focal introductoria, señalizaciones: confirmaciónreformulación-elaboración y repetición, cuadro C-Q-A lorganizador gráfico aplicado antes y después de los trabajos de campo) y discusiones guiadas (DíazBarriga y Hernández, 2002); todo ello para la recolección de datos e información obtenidos in situ. Durante toda la actividad los docentes actuaron como mediadores del aprendizaje y los estudiantes tuvieron la oportunidad de toparse y enfrentarse, por iniciativa propia y organizados en equipos, con el entorno circundante.
Los trabajos de campo fueron evaluados a través de la consignación de un informe por cada equipo de estudiantes a los profesores de la cátedra cuyos datos sivieron de hallazgos al presente estudio. También los docentes hicieron anotaciones en sus libretas de campo sobre los acontecimientos suscitados durante las actividades didácticas desarrolladas, incluyendo las conclusiones de las mini sesiones de discusión de los participantes.

De igual forma, los aportes suministrados por el cuadro C-Q-A $/ C=$ ¿Qué conozco?, ¿Qué quiero conocer? y ¿Qué aprendí?) (Díaz-Barriga y Hernández, 2002), junto al resto de las fuentes de información mencionadas, sirvieron de insumos para sistematizar los resultados de la investigación.

El estudio fue de campo dado que la data (información) o resultados obtenidos se recopilaron directamente en los ambientes geográficos (bosques xerófilo y de manglar) donde se desarrollaron las estrategias didácticas y las prácticas vivenciales. También la investigación se catalogó como no experimental dado que no se manipuló la variable objeto de estudio.

El carácter documental del presente estudio consistió en la realización de revisiones bibliográficas de los fundamentos epistemológicos que 
sustentan la teoría del andamiaje de Bruner (1975), del aprendizaje significativo de Ausubel (1976), del aprendizaje sociocultural de Vigotsky (1979) y evolucionista de Toulmin (Siqueira y Porlán, 1997; Vera et al., 2015).

\section{RESULTADOS Y DISCUSIÓN}

\section{Explicitación de objetivos}

La ejecución de las actividades del trabajo de campo se logró de forma óptima dado que hubo claridad y comprensión, por parte de los estudiantes, de la manera como se iban a desarrollar cada una de ellas (metodología). Esto se alcanzó, en gran parte, la explicitación de los objetivos que hizo el docente al inicio del trabajo. Las dudas e inquietudes, que surgían durante la ejecución de los trabajos de campo, fueron aclaradas por el docente.

\section{Cuadro C-Q-A}

El cuadro C-Q-A es un organizador gráfico, aplicado a los estudiantes, que consiste en la formulación de tres interrogantes autorreflexivas, es decir, los participantes se preguntan a sí mismos y de esta manera responder en relación al conocimiento que posee cada participante sobre los ecosistemas que va a visitar (¿̇Qué conozco?), la información nueva que desea conocer de dichos ambientes (¿̨Qué quiero conocer?) y finalmente se expresan los testimonios, por escrito, referentes a lo que se aprendió, luego de realizados los trabajos de campo, (¿̇Qué aprendí?) acerca de los mismos.

La aplicación del organizador gráfico cuadro C-Q-A permitió indagar sobre el conocimiento que poseían los participantes, antes del inicio de los trabajos de campo, a través de la formulación de la interrogante $\mathrm{C}=$ ¿Qué conozco?, planteada a cada estudiante. Con el uso de esta estrategia se obtuvo información sobre las ideas previas que tenían los aprendices sobre el bosque xerófilo y de manglar, las mismas se agruparon en cuatro y ocho categorías para estos ecosistemas respectivamente, ver Tabla 1 y 2.

Estos conocimientos previos se convirtieron en una información didáctica valiosa tanto para el docente como para los estudiantes.

En el caso del profesor, las preconcepciones le permitieron actuar como mediador en el proceso exploratorio de los estudiantes en el campo, a solicitud de los mismos participantes, en casos como: aclarar situaciones de aprendizaje, enriquecer conocimientos y fortalecer explicaciones, basándose en esas ideas primarias cognitivas de los aprendices. Estos hallazgos coincidieron con lo señalado por Ausubel (1976), quien expone que el docente debe conocer sobre las preconcepciones de sus estudiantes, y a partir de ello enseñar en cuestión.

También para los estudiantes resultó de suma importancia contar con ideas 
previas, dado que éstas conformaron el fundamento teórico conceptual o base cognitiva, aportada por los integrantes de cada equipo, para poder "enfrentar" y abordar las diferentes actividades prácticas durante los trabajos de campo.

De igual manera, el uso del cuadro C-Q-A demostró que el grupo de estudiantes adquirió conocimientos nuevos en relación a los que éstos previamente manejaban, luego de realizados los trabajos de campo y a través de las respuestas emitidas a la pregunta $A=\dot{¿} Q u e ́$ aprendí?, Tablas 1 y 2.

Es importante destacar, que la información obtenida se agrupó en nueve y quince categorías para los ecosistemas de bosque xerófilo y de manglar respectivamente; revelándose de esta forma un incremento sustancial en la información aportada en relación con la correspondiente a las preconcepciones y además del surgimiento de conocimiento novedoso manejado por los participantes (aparición de nuevas categorías). 
Tabla 1. Categorías del ¿Qué conozco? y del ¿Qué aprendí? del cuadro C-Q-A de los trabajos de campo al bosque xerófilo, Reserva de Fauna Silvestre Ciénaga de La Palmita e Isla de Pájaros, estado Zulia, Venezuela

\section{Categorías del ¿Qué conozco?}

A. A. Localización geográfica

B. Condiciones climáticas y edafológicas

C. Flora y fauna característicos

D. Adaptaciones de la flora y fauna

\section{Categorías del ¿Qué aprendí?}

A. Localización geográfica

B. Condiciones climáticas y edafológicas

B.1 Medición de humedad relativa, temperatura y velocidad del viento

C. Flora y fauna característicos

C.1 Características morfo-anatómicas (descripción de cactáceas)

C.2 Necromasa

C.3 Bacterias y hongos

C.4 Hongos liquenizados

D. Adaptaciones de la flora y fauna

D. 1 Cripsis

D.2 Adaptaciones en cactáceas

D.3 Tricomas en olivo

D.4 Semillas voladoras (dispersión de especies)

D.5 Estomas en criptas

D.6 Hojas pubescentes

E. Interacciones

E.1 Hemiparasitismo (pajarito-olivo)

E.2 Epifitismo (bromelia epífita-planta soporte)

E.3 Comensalismo (trepadora-olivo)

E.4 Mutualismo (hongos liquenizados)

E.5 Interacción entre serpientes

F. Bienes y servicios

F.1 Taninos del dividive

G. Método del muestreo

G.1 Delimitación de cuadratas (parcelas)

H. Recolecta de insectos

I.

I. Alta diversidad biológica evidenciada por el contacto directo 
Tabla 2. Categorías del ¿Qué conozco? y del ¿Qué aprendí? del cuadro C-Q-A de los trabajos de campo al bosque de manglar, Reserva de Fauna Silvestre Ciénaga de La Palmita e Isla de Pájaros, estado Zulia, Venezuela

\section{Categorías del ¿Qué conozco?}

D. A. Localización geográfica

E. Parámetros fisicoquímicos

B. 1 Hipersalinidad

B.2 Suelo fangoso (barroso, pantano, humedal)

B.3 Suelo con poco $\mathrm{O}_{2}$

B.4 Alta concentración de azufre

F. Flora y fauna característicos

C. 1 Presencia de hongos y bacterias

C.2 Descripción de las características morfo-anatómicas de los mangles

C.3 Dimorfismo sexual en cangrejos

D. Adaptaciones de las especies de mangle al medio (halotolerantes)

D. 1 Hidátodos para la excreción de sal

D.2 Neumatóforos para intercambio gaseoso

D.3 Lenticelas para la respiración

D.4 Zancos para fijación al suelo

D.5 Ultrafiltración en raíces

E. Definición del manglar por los mangles

F. Bienes y servicios

G. Ecosistema de alta productividad

$H$. Tipos de mangles

\section{Categorías del ¿Qué aprendí?}

A. Localización geográfica

B. Parámetros fisicoquímicos

B. 1 Hipersalinidad

B.2 Suelo fangoso (barroso, pantano, humedal)

B.3 Suelo con poco $\mathrm{O}_{2}$

B.4 Alta concentración de azufre

B.5 Medición de parámetros (humedad relativa, pH, salinidad,

temperatura)

B.6 Olor desagradable por $\mathrm{H}_{2} \mathrm{~S}$ (Sulfuro de hidrógeno)

C. Flora y fauna característicos

C.1 Presencia de hongos y bacterias

C.2 Descripción de las características morfo-anatómicas de los mangles

C.3 Dimorfismo sexual en cangrejos

C.4 Uso de nombres científicos en algunas especies

D. Adaptaciones de las especies de mangle al medio (halotolerante)

D. 1 Hidátodos para la excreción de sala

D.2 Neumatóforos para intercambio gaseosob

D.3 Lenticelas para la respiraciónc

D.4 Zancos para fijación al suelo

D.5 Ultrafiltración en raíces

E. Definición del manglar por los manglesd

F. Bienes y servicios

G. Ecosistema de alta productividade

H. Tipos de mangles

I. I. Reproducción de los mangles

II. I.1 Criptoviviparía

III. $\quad 1.2$ Viviparías

J. Ecotono

K. Zonación 
Continuación Tabla 2. Categorías del ¿̇Qué conozco? y del ¿̇Qué aprendí? del cuadro C-Q-A de los trabajos de campo al bosque de manglar, Reserva de Fauna Silvestre Ciénaga de La Palmita e Isla de Pájaros, estado Zulia, Venezuela

\begin{tabular}{ll}
\hline Categorías del ¿Qué conozco? & Categorías del ¿Que aprendí? \\
\hline & L. Componentes bióticos predominantes \\
& L.1 Mangle rojo \\
L.2 Cangrejos & M. Método de muestreo (parcela) \\
N. Interacciones & N.1 Defoliación (cangrejos e insectos) \\
N.2 Necrosis foliar (hongos y bacterias) & O. Efectos antropogénicos \\
O.l Tala & O.2 Desechos sólidos \\
P. Recolecta de muestras botánicas
\end{tabular}

aUn parcipante manifestó que eran hidátodos modificados, bLos estudiantes lograron diferenciar los neumatóforos de mangle blanco y mangle negro, cLos aprendices evidenciaron solo su presencia en mangle rojo, dAlgunos estudiantes se sorprendieron porque anteriormente no habían visto un bosque de manglar, eSe relacionó con la observación de abundante materia orgánica en el suelo, fSe describió como característica común de los mangles blanco y negro, aSe describió como característica propia del mangle rojo. 


\section{Focal introductoria}

En el desarrollo de la actividad se establecieron diálogos entre los estudiantes, y entre éstos y los profesores. Los docentes corroboraron que la estrategia focal introductoria promovió en los educandos el reconocimiento de características anatómicas modificadas de algunos seres vivos, y también permitió que éstos dedujeran que las mismas correspondían a adaptaciones ecológicas al ambiente en cuestión.

En esta explicación se señaló el ejemplo en el cual el docente logró concentrar la atención de los estudiantes al practicar un corte al tallo de un cactus columnar ("cardón de dato", Stenocereus griseus de la familia Cactaceae) y formuló una serie de interrogantes sobre lo observado que conllevó a los estudiantes a participar, y respondieron que este órgano presentaba una anatomía suculenta para la reserva de agua y carbohidratos, concluyendo así que este rasgo correspondía a una adaptación de la especie vegetal (planta adaptada a condiciones de sequía) que habita en el bosque xerófilo, Tabla 3.

De igual forma, esta estrategia facilitó a los estudiantes la identificación de elementos del contenido temático niveles ecológicos, dado que éstos fueron capaces de reconocer y comparar los caracteres morfológicos externos (fenotipo) de una agrupación de organismos (componentes bióticos) presentes en la escala espacio-temporal específica del ecosistema explorado. En esta ocasión, el profesor dirigió la observación de los educandos a un conjunto de plantas dispuestas en forma de roseta, con hojas alargadas, duras, puntiagudas y de bordes aserrados llamadas bromelias ("maya", Bromelia humilis de la familia Bromeliaceae). La interrogante formulada por el docente se centró en plantear żqué les llama la atención de lo observado? Tabla 3. 
Tabla 3. Procesos básicos activados en estudiantes en trabajos de campo al bosque xerófilo y de manglar, Reserva de Fauna Silvestre Ciénaga de La Palmita e Isla de Pájaros, estado Zulia, Venezuela.

\begin{tabular}{|c|c|c|}
\hline Estrategia aplicada & Experiencia & Procesos básicos generados* \\
\hline \multirow[t]{2}{*}{ 1. Focal introductoria } & 1. Corte del tallo del cactus columnar & $\begin{array}{l}\text { 1. Fijación de la atención } \\
\text { 2. Mejoramiento de la observación (agudeza visual) } \\
\text { 3. Comparación } \\
\text { 4. Discusión } \\
\text { 5. Manejo y uso de material biológico } \\
\text { 6. Identificación } \\
\text { 7. Interconexión de conocimiente Botánica } \\
\text { (planta de la familia Cactaceae) }\end{array}$ \\
\hline & 2. Población de bromelias & $\begin{array}{l}\text { 1. Fijación de la atención } \\
\text { 2. Observación (tamaño, hábito de vida) } \\
\text { 3. Interconexión de conocimientes Genética } \\
\text { (fenotipo) } \\
\text { 4. Interpretación Nivel ecológico (población de } \\
\text { bromelias), reafirmación de conceptos }\end{array}$ \\
\hline $\begin{array}{l}\text { 2. Señalizaciones: confirmación- } \\
\text { reformulación-elaboración y } \\
\text { repetición }\end{array}$ & 3. Neumatóforos & $\begin{array}{l}\text { 1. Observación (visual, táctil) } \\
\text { 2. Interacción profesores-estudiantes } \\
\text { 3. Uso, manejo y dominio del lenguaje biológico } \\
\text { 4. Análisis y discusión } \\
\text { 5. Interpretación compleja }\end{array}$ \\
\hline $\begin{array}{l}\text { 3. Discusión guiada (situación de } \\
\text { aprendizaje) }\end{array}$ & $\begin{array}{l}\text { 4. Caracteres morfo-anatómicos de } \\
\text { plantas cactáceas }\end{array}$ & $\begin{array}{l}\text { 1. Fijación de la atención } \\
\text { 2. Mejoramiento de la observación (agudeza visual) } \\
\text { 3. Comprensión } \\
\text { 4. Discusión } \\
\text { 5. Análisis } \\
\text { 6. Manejo y uso de material biológico } \\
\text { 7. Identificación }\end{array}$ \\
\hline
\end{tabular}

* Relacionados con la experiencia de los docentes 
Continuación Tabla 3. Procesos básicos activados en estudiantes en trabajos de campo al bosque xerófilo y de manglar de la Reserva de Fauna Silvestre Ciénaga de La Palmita, estado Zulia, Venezuela

\begin{tabular}{|c|c|c|}
\hline Estrategia aplicada & Experiencia & Procesos básicos generados* \\
\hline \multirow[t]{3}{*}{$\begin{array}{l}\text { 3. Discusión guiada (situación de } \\
\text { aprendizaje) }\end{array}$} & 5. Planta cactácea con hojas & $\begin{array}{l}\text { 1. Fijación de la atención } \\
\text { 2. Ideas previas (hicieron uso de ideas previas } \\
\text { recientes) } \\
\text { 3. Observación (agudeza visual) } \\
\text { 4. Manejo y uso de material biológico } \\
\text { 5. Comparación } \\
\text { 6. Análisis } \\
\text { 7. Inferencia } \\
\text { 8. Conclusión } \longrightarrow \text { Es una planta cactácea }\end{array}$ \\
\hline & $\begin{array}{l}\text { 6. Características morfo-anatómicas de } \\
\text { los mangles }\end{array}$ & $\begin{array}{l}\text { 1. Fijación de la atención } \\
\text { 2. Observación (visual, táctil) } \\
\text { 3. Descripción } \\
\text { 4. Comparación } \\
\text { 5. Discusión } \\
\text { 6. Análisis } \\
\text { 7. Identificación de las especies de mangle }\end{array}$ \\
\hline & $\begin{array}{l}\text { 7. Adaptaciones de las especies de } \\
\text { mangle al ambiente }\end{array}$ & $\begin{array}{l}\text { 1. Fijación de la atención } \\
\text { 2. Observación (visual y gustativa) } \\
\text { 3. Identificación } \\
\text { 4. Discusión } \\
\text { 5. Análisis } \\
\text { 6. Manejo y uso de material biológico (hojas) }\end{array}$ \\
\hline
\end{tabular}

*Relacionados con la experiencia de los docentes 
A partir de allí los estudiantes respondieron que se trataba de un ejemplo de población integrada por 25 plantas llamadas bromelias (parecidas a la "piña"), localizada en el bosque xerófilo de la Reserva de Fauna Silvestre Ciénaga de La Palmita del Municipio Santa Rita en el Estado Zulia, Tabla 3.

\section{Señalizaciones: confirmación- reformulación-elaboración repetición}

El uso de las señalizaciones: confirmación, reformulación, elaboración y repetición, contribuyó a que los diferentes equipos de estudiantes abordarán situaciones en el campo, de acuerdo a su espíritu de curiosidad, intereses e inquietudes, que no se presentaban de manera muy clara y fácilmente evidentes (incógnitas difíciles de descifrar), y sobre los cuales centraba su atención y se sentían cautivados. Esto estimuló a los aprendices a la conformación de conversatorios de discusión en los que cada participante proponía su punto de vista o explicación para llegar a conclusiones reveladoras sobre el tema tratado.

Por ello, la constatación visual, la verificación de la "situación problema" través del contacto físico (tocar y palpar) y el intercambio de ideas por parte de los estudiantes, además de la participación de los docentes como mediadores en la reestructuración y manejo de las conceptualizaciones, originaron que se alcanzara un consenso entre los aprendices para el manejo correcto del conocimiento ecológico de la temática abordada.

En tal sentido, se indicó el ejemplo de unas estructuras anatómicas cilíndricas de 8-10 cm de altura, dispuestas en sentido vertical en el sustrato del manglar y a "pie de árbol" de los árboles de "mangle negro" Avicennia germinans de la familia Aviceniaceae, que se convirtió en un verdadero tema controversial entre los educandos integrantes de un mismo equipo, así como también a nivel de los diferentes grupos de estudiantes.

Luego que los estudiantes realizaron planteamientos argumentados y expresaron propuestas defendidas por sus seguidores que daban la explicación acerca de lo tratado, y dada la situación abordada, el docente expresó: ¿qqué son estas "puntas" de madera que sobresalen del suelo?, lo que generó diferentes opiniones, agrupadas todas estas en tres respuestas, sobre las estructuras observadas son: 1) "palitos", 2) raíces y 3) plántulas.

Para ello, el docente propuso a algunos de los partidarios de cada propuesta que expusieran los argumentos que fundamentaban su postura.

Durante el planteamiento de las explicaciones, algunas de las respuestas fueron descartadas luego de ser analizadas y debido a su inconsistencia lógica como fue el caso de que las estructuras correspondieran a "palitos", definidos estos como fragmentos 0 pedazos de estructuras de consistencia semileñosa parecidos a la madera, que 
sobresalían del suelo y que se encontraban dispuestos de manera vertical.

Los profesores también propusieron a algunos estudiantes que extrajeran 0 arrancaran una de estas estructuras del suelo (confirmación), Tabla 3. Luego de llevar a cabo esta práctica se corroboró que las estructuras estaban fuertemente unidas a algo que debido a la gran dificultad para ser desprendidas, no era el sustrato (suelo); razón por la cual no se podía concluir que se trataran de plántulas de mangle (reformulación), Tabla 3.

Además de ello, los estudiantes pudieron comprobar que tampoco poseían las caraterísticas que identifican plenamente a una plántula como son un pequeño tallo, hojas y raíces enterradas en el sustrato (confirmación).

Finalmente, y apoyado en las acciones llevadas a cabo, además de las condiciones del sustrato de manglar, reveladas por algunos estudiantes, referentes a que dicho sedimento es pobre en oxígeno (condiciones de hipoxia a anaeróbicas), se confirmó que las estructuras correspondían a raíces respiratorias empleadas para el intercambio gaseoso llamadas neumatóforos por algunas especies de mangles (elaboración), Tabla 3.

En cuanto a lo expresado, Toulmin sostiene que la evolución de los conceptos se basa en la existencia de distintas variantes en competencia (en el ejemplo expuesto: "palitos", raíces y plántulas) dentro de un conjunto poblacional dado, al igual que los mecanismos ambientales, que por presión exterior $\mathrm{U}$ obtención de más méritos se seleccionan las mejores variedades en relación a un determinado contexto espaciotemporal y según las exigencias allí establecidas (Siqueira y Porlán, 1997; Vera et al., 2015).

Lo expuesto indujo a los estudiantes a inclinarse a favor de un postulado (selección de una de las opciones), luego de la verificación de las evidencias que se plantearon de cada una de las diferentes alternativas en debate. De esta forma se presentó un equilibrio entre continuidad y cambio que explica la permanencia de la innovación o la ruptura epistemológica; este doble mecanismo de selección crítica y de producción de innovaciones es el motor del desarrollo de la evolución conceptual (Siqueira y Porlán, 1997).

Por otra parte, el conjunto de actividades realizadas a través de la estrategia señalizaciones: (confirmaciónreformulación-elaboración y repetición) reveló la utilización del enfoque epistemológico constructivista en el cual también se fundamenta la teoría evolucionista de Toulmin de acuerdo a Mellado y Carracedo (1983).

Esta ejemplificación del trabajo de campo en el manglar demostró los elementos que viabilizan la construcción del conocimiento, y por ende promueven el aprendizaje (González, 2001), como son:

1. La interacción entre los estudiantes, a través de un intercambio de ideas (discusión y análisis), para afirmar y 
explicar que las estructuras anatómicas se trataban de neumatóforos.

2. Durante la actividad didáctica los aprendices se mantuvieron en contacto directo (in situ) con la estructura anatómica objeto de estudio, sobre la cual se fijó la atención y se hicieron observaciones (imagen visual y táctil) para corroborar y descartar los argumentos empleados, y a partir de estas indagaciones se hicieron las explicaciones correspondientes.

3. El uso de las preconcepciones (conceptos de Botánica sobre anatomía y morfología de las raíces, las condiciones anaeróbicas del sustrato donde habitan los mangles, entre otros) por parte de los estudiantes, además de su conexión con el conocimiento develado, demostró que el mismo resultó significativo.

También todo esto le permitió a los aprendices a comprender el funcionamiento de los mangles dentro del ecosistema de manglar, escenario didáctico natural que resultó novedoso para gran parte de los participantes.

\section{Discusiones guiadas}

Las discusiones guiadas se refirieron a situaciones encontradas en el campo sobre las cuales los estudiantes exploraron y hallaron material biológico que despertó su interés y ameritó una discusión intra-grupos, inter-grupos y con la participación de los docentes en calidad de mediadores y orientadores, para indagar, viabilizar, reforzar y lograr la consolidación y adquisición nuevos conocimientos.

Durante los trabajos de campo los estudiantes mantuvieron un contacto directo y permanente con la naturaleza, que les permitió llevar a cabo actividades exploratorias a fin de abordar, descubrir y seleccionar situaciones de aprendizaje asociadas a temáticas ecológicas. Estas acciones promovieron la discusión a nivel de los equipos de participantes y guiadas por los profesores para el enriquecimiento del conocimiento individual y grupal. A continuación se describen algunas de las situaciones de aprendizaje:

\section{Situación de aprendizaje 1. Caracteres morfo-anatómicos de plantas cactáceas}

Estudiantes..."aprendimos sobre los diferentes tipos de cactus que para nosotros eran iguales y pudimos detallar las diferentes características que estos poseen como es el tamaño y disposición de las espinas que son hojas modificadas, el color de los tallos, la separación de las espinas, el color y la forma del fruto", Tabla 3.

La cita anterior reveló el papel protagónico que desempeñó la fijación de la atención y la observación (imágenes visuales), para que los aprendices lograran discernir de forma inequívoca la identificación de seres vivos, haciendo uso de los detalles de los caracteres externos de los organismos abordados (descripción). 
La actividad exploratoria en una de las estaciones brindó a los participantes la oportunidad de lograr identificar, comparar, diferenciar, discutir y analizar de forma práctica algunas especies de cactus columnares, Tabla 3.

Para ello, los estudiantes centraron sus observaciones, y con orientación de los docentes, sobre aquellos rasgos y detalles botánicos que evidenciaron características diferenciales entre las especies, como eran color del tallo, número, grosor y longitud de las espinas, agrupación de las espinas en aureolas, forma y color del fruto, entre otras.

\section{Situación de aprendizaje 2. Planta cactácea con hojas ("guamacho", Pereskia guamacho de la familia Cactaceae).}

Estudiantes..."nos causó gran admiración la presencia de hojas en un tipo de cactus ya que pensábamos que ningún cactus tenía hojas, sino que solo poseían sus espinas que son sus hojas modificadas, y pudimos obtener ese conocimiento que anteriormente estaba errado", Tabla 3.

El párrafo anterior reveló un "choque cognitivo" generado entre las preconcepciones sobre la temática tratada y la experiencia innovadora de aprendizaje a la que se enfrentaron los estudiantes; lo que finalmente conllevó a la incorporación de este nuevo conocimiento y por ende a una reestructuración conceptual.

En relación a lo expresado, Toulmin sostiene que lo racional de las actividades intelectuales no está asociado con la coherencia interna de los conceptos, ni con las creencias habituales de un individuo, sino con la manera con que cada persona es capaz de modificar su posición intelectual frente a experiencias nuevas e imprevistas (Siqueira y Porlán, 1997).

Esto experiencia permitió generar una reorganización de las ideas en los esquemas mentales de los estudiantes, reconocer e incluir los aspectos novedosos previamente desconocidos y que los educandos asumían que prácticamente eran improbables que existieran.

La experiencia con la planta de "guamacho" (cactácea con hojas) se presentó cuando algunos estudiantes fueron capaces de fijar la atención y reconocer la similitud anatómica y la forma como se disponían las espinas en el tallo de este árbol (observación) en comparación con las correspondientes a los cactus columnares previamente identificados; esto les permitió analizar y finalmente concluir y afirmar que esta planta también correspondía a una especie de cactácea, Tabla 3, aunque la misma presentara un rasgo estructural incongruente e improbable para ellos, como lo es la presencia de hojas.

Esta situación se presentó luego que los estudiantes ya habían identificado y comparado, previamente, varias especies de cactus columnares a partir de los detalles botánicos, incluyendo la disposición de las espinas, señalados en la situación de aprendizaje 1, Tabla 3. 


\section{Situación de aprendizaje Características morfo-anatómicas de los mangles}

Estudiantes..."nos maravillamos con los diferentes tipos de mangles, particularmente nos encantó el mangle rojo, fue algo espectacular ver como sus raíces tan grandes sobresalen, solo podíamos apreciar esto por televisión, videos o en libros pero verlos, tocarlos es comprobar que existen y que son reales", Tabla 3.

La cita anterior destacó la "potente energía didáctica" que posee la experiencia vivencial del contacto directo con la naturaleza (observación táctil y visual) y el uso y manejo de material biológico in situ como actividades prácticas de gran riqueza e importancia para corroborar, afianzar conocimientos y lograr nuevos aprendizajes, Tabla 3.

El reconocimiento diferencial de las especies de mangle constituyó uno de los principales retos motivacionales logrados por los estudiantes durante los trabajo de campo realizados al ecosistema de manglar. Para ello, la gran mayoría de los equipos de educandos recolectó material botánico (hojas, raíces, flores, frutos, porciones del tallo, plántulas y cortezas) de los diferentes mangles e hicieron comparaciones y discusiones a objeto de lograr la distinción y determinación (identificación) de cada una de dichas especies, Tabla 3.

\section{Situación de aprendizaje 4. Adaptaciones de las especies de mangle al ambiente}

Estudiante..."observamos

directamente las adaptaciones que tienen estos árboles, por ejemplo, visualizamos los cristales de sal en el haz de la hoja e incluso los probamos y eran verdadera sal", Tabla 3.

De igual manera, que en situaciones de aprendizaje anteriores, en esta nueva experiencia cognitiva se manifestó el poder que ejerce la fijación de la atención y la observación (imágines visuales y gustativas) para describir e identificar rasgos físicos clave e importantes de los seres vivos. Así como también se mostró evidencia del mecanismo que operó para explicar la interrelación de la planta con el ambiente (sistema de eliminación del exceso de sal de la planta) y de esta manera se promovió la construcción del conocimiento, Tabla 3.

La relación de las especies de mangle con los parámetros fisicoquímicos que identifican al ecosistema manglar (interacción abiótica-biótica), además del fundamento teórico manejado por algunos participantes, marcó la pauta para que los equipos estudiantiles indagaran sobre las adaptaciones especializadas de estas especies botánicas particulares a su ambiente.

A objeto de alcanzar tal desafío, se promovió en los aprendices la observación, el intercambio de ideas, la discusión, la consulta a los docentes, el 
análisis, la interconexión de conocimientos, el manejo y uso del material biológico, la interdependencia compleja, entre otros aspectos, Tabla 3.

En concordancia a los planteamientos realizados en las situaciones de aprendizaje descritas previamente, se ha señalado que las metodologías basadas en los descubrimientos guiados proporcionan a los estudiantes oportunidades para manipular de forma activa y realizar actividades que los animen a buscar, explorar, analizar o procesar de alguna otra manera la información que reciben en lugar de solo responder a ella.

\section{Vinculación de algunas teorías de aprendizaje con las actividades realizadas en los trabajos de campo}

Las diferentes actividades didácticas desarrolladas durante la realización de los trabajos de campo al bosque xerófilo y de manglar permitieron afirmar que en ellas se puso de manifiesto la aplicación de los fundamentos básicos de algunas teorías del aprendizaje.

En el caso de la teoría del aprendizaje significativo de Ausubel (1976) se demostró el rol protagónico que tiene el uso de las ideas previas como "piso" o base cognitiva preexistente para así poder incorporar ("encajar o engranar") el conocimiento novedoso recientemente obtenido. Esto le confirió además un rasgo de sentido valorativo y de estimación al conocimiento nuevo que los estudiantes incorporaron a sus marcos conceptuales.
En la situación de aprendizaje referente a la identificación detallada de las especies de mangle, lograda por los estudiantes en el campo, éstos dieron inicio a esta actividad partiendo del conocimiento teórico que poseían sobre la existencia de diversas .especies denominadas mangle rojo, mangle blanco, mangle negro y mangle de botoncillo, sin saber sobre el reconocimiento y la distinción de una especie en relación a la otra. La conjunción de la experiencia cognitiva previa y la obtenida en los trabajos de campo fortalecieron y enriquecieron de forma significativa el conocimiento sobre estas especies vegetales.

Los aportes de la teoría de Vigotsky (1979) se manifestaron en los trabajos de campo a través del papel mediador de los docentes en todas las situaciones de aprendizaje. Aunado a esto se debe destacar que el desempeño de los estudiantes, en equipos de tres participantes, promovió la repartición de responsabilidades, roles y tareas, así como también el compartir o refutar las opiniones que se tenían sobre las discusiones y análisis que se presentaban; resultando todo esto en una interacción socializadora.

De igual modo, las actividades prácticas como la recolecta de muestras botánicas y zoológicas, la descripción de detalles morfoanatómicos de las especies, entre otras situaciones, demandó la consulta y ayuda mutua (cooperativa) de los compañeros participantes, apoyadas en la teoría sociocultural. Todas estas prácticas de sinergismo entre los 
educandos resultaron en un mejor afianzamiento de los conocimientos aprendidos durante los trabajos de campo.

Por otra parte, el concepto de "andamiaje" de Bruner (1975) estuvo presente durante el desarrollo de los trabajos de campo y representado por las estrategias de enseñanza para promover el aprendizaje de los estudiantes; destacando, además de ello, que el campo demostró ser un escenario didáctico que contribuyó al cumplimiento de estas estrategias.

\section{CONCLUSIONES}

Las experiencias y estrategias didácticas alcanzadas y desarrolladas durante los trabajos de campo conjugaron la participación activa de los estudiantes, el uso de sus conocimientos previos para la adquisición de nuevas conocimientos y la consolidación de novedosos aprendizajes ecológicos.

La observación directa y vivencial se constituyó en la herramienta principal para que los estudiantes se abrieran paso ante los deslumbrantes aportes didácticos del campo.

\section{REFERENCIAS}

Acosta Faneite, S. y Boscán Andrade, A. (2014). Estrategias de enseñanza para promover el aprendizaje significativo de la Biología en la Escuela de Educación, Universidad del Zulia. Multiciencias, 14(1), 67-73

Ausubel, D. (1976). Psicología educativa: un punto de vista cognoscitivo. Trillas. México
Bruner, J. S. (1975). Early social interaction and language acquisition. London: Academic Press

Di Salvo, A., Romero, N. y Briceño, J. (2009). Estudio de los ecosistemas desde la perspectiva de la complejidad. Multiciencias, 9(3), 242-248

Díaz-Barriga, F., y Hernández, G. (2002). Estrategias docentes para un aprendizaje significativo. Una interpretación constructivista. Segunda Edición. Editorial McGrawHill. México. $465 \mathrm{p}$

Fernández Manzanal, R. y Casal Jiménez, M. (1995). La enseñanza de la Ecología. Un objetivo de la Educación Ambiental. Enseñanza de las Ciencias, 13(3), 295-311

González, A. (2001). Un vistazo al constructivismo. Correo del Maestro, 65, 21-24

Mellado, V. J. y Carracedo, D. (1983). Contribuciones a la filosofía de la ciencia a la didáctica de las ciencias. Enseñanza de las Ciencias, $11(3), 331-339$

Sauwéns, A. (1988). Política institucional de un programa de trabajo de la Geografía a Nivel Superior. Trabajo de ascenso. Maracay, Universidad Pedagógica

Experimental Libertador, Instituto Pedagógico Maracay

Siqueira, J. B. y Porlán, R. (1997). La epistemología evolucionista de Stephen Toulmin y la enseñanza de las ciencias. Investigación en la Escuela, 39, 17-26

Vera, A. (2007). ¿Para qué enseñar Ciencias Naturales en la Educación General Obligatoria?. Seminario Fundamentos para la Enseñanza de las Ciencias. Doctorado en Ciencias Humanas, Facultad de Humanidades y Educación, Universidad del Zulia, Maracaibo, 
Venezuela. Consultado: 10 de Mayo de 2019. Disponible en: http://www.foroswebgratis.com/tem a-

Vera, A., Fernández, O. y Bravo de Nava, E. (2015). Teoría evolucionista de Toulmin: fundamento epistemológico para el aprendizaje de la Ecología. Multiciencias, 15(2), 156-162

Vigotsky, L. (1979). El desarrollo de los procesos superiores. Editorial Crítica. Barcelona, España 